\title{
O FLUXO DE CAIXA NO SETOR RURAL (conforme alguns estudos nos Estados Unidos)
}

\author{
Autor: José Carlos Marion \\ Professor Associado do Departamento de Contabilidade e Atuária da FEA/USP
}

Cremos que a experiência e os constantes debates sobre o uso do Fluxo de Caixa como principal relatório contábil no setor rural nos Estados Unidos são de grande interesse não só para a comunidade agropecuária brasileira, como também para os demais setores contábilfinanceiro, já que há uma forte corrente para que este relatório seja exigido por lei no Brasil.

1) Contabilidade a base do caixa (método de caixa)

Segundo Penson e Lins ${ }^{1}$ este é o método que a maioria dos negócios agropecuários usa nos EUA, dado a sua simplicidade em considerar apenas os recebimentos e pagamentos. Na década passada ${ }^{2}$ quase a totalidade dos pequenos agropecuáristas usava este método, onde o lucro no ano (resultado) é obtido subtraindo das vendas recebidas as despesas pagas. Acréscimos nos estoques agropecuários resultantes da atividade operacional não são considerados lucro por este método, mas a acumulação de insumos como fertilizantes e outros são considerados uma despesa do ano a partir do momento em que eles são pagos. Portanto, despesas como depreciação de prédios e máquinas, produtos consumidos pela família etc, não são considerados como tais, pois não representam um efetivo desembolso de caixa.

Há diversas vantagens no uso deste método aos olhos de muitos administradores rurais nos EUA. Uma delas e a sua simplicidade. Ao assumir este método o agropecuarista evita manter registros detalhados de estoques, depreciação etc. Além disso, reduz o pagamento, a princípio, de Imposto de Renda, por ocasião da compra de insumos à vista no ano corrente, admitindo que pelo menos parte dele será usado no ano seguinte. Assim os administradores rurais podem controlar as flutuações anuais nos seus lucros tributáveis - e, portanto, no seu Imposto de Renda devido pela manipulação do momento da venda e compra dos seus insumos.

Em relação aos pecuaristas que estão continuamente expandindo suas operações, usando este método podem evitar desembolso com Imposto de Renda por um período de tempo, aumentando seu caixa líquido. Isto porque parte da sua criação mantida para crescimento/engorda (que provoca desembolso no caixa) será reconhecida antes da venda do gado (entrada dos recursos resultante da venda). Dessa forma, consideram-se os desembolsas no caixa para a criação do rebanho mas não se considera o ganho do crescimento, provocando uma seqüência de redução do lucro tributável enquanto houver expansão do rebanho.

Os produtores rurais também reconhecem algumas desvantagens que este método poderia ocasionar. Uma delas é a ocorrência da venda de uma produção que estava acumulada, como esperando um melhor preço. Estas vendas provocam um abrupto crescimento no lucro e conseqüentemente no Imposto de Renda a pagar. Uma outra desvantagem é que

\footnotetext{
${ }^{1}$ Agriculture Finance - An Introduction to Micro and Macro Concepts. John B. Penson Jr. e David A. Lins -Prentice - Hall, mc. 1980.

2 The Tax Reform Act of 1986 - W Ayer e Gavle S. Willett - Westem Regional Extension. Publication 106, DerJ87 Universidade de Arizona.
}

Caderno de Estudos nº 09 - São Paulo - FIPECAFI, Outubro de 1993 
através deste método é proibido reduzir do lucro que gera o Imposto de Renda certas reduções (perdas) no ano corrente referentes a colheitas e animais.

Por outro lado, o regime de competência é o preferido pelos profissionais contábeis, pois não há distorção na apuração do resultado (como ocorre no regime caixa); o lucro é reconhecido no ano em que ele é gerado (mesmo que não tenha ainda se transformado totalmente em caixa). Através deste método é possível reconhecer as perdas na produção e no rebanho em estoque. Estas perdas reduzem o lucro tributável, diminuindo, portanto, o imposto devido.

Enquanto a simplicidade caracteriza o método a base do caixa [tornando-se uma vantagem], a complexidade representa uma desvantagem para o uso da Contabilidade no regime de competência, principalmente para pequenos e médios negócios agropecuários, envolvendo um quadro muito mais amplo de registros contábeis. De maneira geral a utilização do regime caixa num ne9oclo agropecuário em expansão propicia, nos EUA, como já vimos, a principio, reduções de Imposto de Renda.

Em termos de Imposto de Renda no Brasil destacamos que, para a Pessoa Física, a apuração do resultado é à base do Regime Caixa, não sobrando alternativa para o agropecuarista. Todavia, ainda que poucos, há aqueles que fazem Contabilidade pelo Regime de Competência pensando num sistema de informação mais adequado para a tomada de decisão.

No que tange à Pessoa Jurídica, a tributação do Imposto de Renda incide sobre o resultado apurado pelo Regime de Competência, com ajustes adicionais previstos pelo Regulamento do Imposto de Renda. Dessa forma, para fins fiscais, a Contabilidade à base de caixa não tem valor algum.Mostraremos, a seguir, principalmente para esta situação, o quanto é importante trabalhar concomitantemente com o Fluxo de Caixa, ainda que não traga benefícios fiscais no que tange à realidade brasileira.

2) A Demonstração do Fluxo de Caixa e a sua Importância na Agropecuária quando integrada com o Fluxo Econômico.

A partir de 1989 a Demonstração do Fluxo de Caixa (DFC) tomou-se obrigatória nos EUA, compondo o conjunto das demonstrações financeiras.

A DFC ajuda, entre outras utilidades, a avaliar o potencial da empresa em gerar fluxos futuros de caixa, a honrar seus compromissos, pagar dividendos e identificar sua necessidade de recursos financeiros externos. A DFC evidencia melhor as razões das diferenças entre o lucro líquido e as entradas (recebimentos) e saídas (pagamentos), bem como os efeitos na posição financeira da empresa resultante das transações financeiras e não financeiras (operações que não afetam o caixa) durante um período.

Observações interessantes nesta área são colocadas pelo professor Thomas Frey da Universidade de Illinois e pelo pesquisador Arnold Oltmans daquela mesma universidade, mostrando que a DFC é um instrumento importante para analisar a ligação entre o saldo de caixa líquido evidenciado no Balanço Patrimonial e o Lucro Líquido obtido através do regime de competência ${ }^{3}$. Um exemplo desta reconciliação é mostrado nos Anexos 1 e 2. através de um estudo de caso.

Normalmente as instituições que concedem crédito rural avaliam o passado e querem projetar o desempenho futuro da empresa para tomar a decisão mais adequada na estipulação e concessão do crédito. Segundo os autores acima citados, os emprestadores de recursos analisam a viabilidade de um retorno de pagamento (ou seja, a capacidade de pagamento do tomador do empréstimo) a curto prazo através da DFC e a lucratividade (considerando a diferença entre receita e despesa) através da Demonstração de Resultado, feito a base do regime de competência.

${ }^{3}$ (3) The Statement of Cash Flows - Thomas Frey e Arnold Otmans - AGRI Finance - 4/89 - Universidade de Illinois. 
Tudo isto porque uma empresa pode gerar caixa sem ter lucro (venda de estoque a preço baixo, venda de ativo permanente, acréscimo de contas a pagar), concluindo-se que só o caixa não revela todos os fatos. Por outro lado, uma empresa pode ter lucro e concomitantemente não conseguir pagar seus compromissos, sendo que só a apuração do resultado a base de competência não mede a verdadeira saúde financeira da empresa. Assim a combinação dos dois fluxos (financeiro e econômico) permite uma melhor análise dos emprestadores do dinheiro.

Para a finalidade de uma boa análise a DFC é dividida em três grupos:

a) Atividade Operacional, envolvendo a produção e venda de bens e serviços relativos a atividade operacional da empresa. No setor rural haveria necessidade de subtrair a retirada de dinheiro para a manutenção da família que corresponde a salários de trabalho e administração dos mesmos.

b) Atividade Referente a Investimento, focalizando o fluxo de caixa para compra e venda de bens de capital (máquinas, implementos agrícolas), animais de reprodução (criação), planos de aposentadoria etc.

c) Atividade Financeira, incluindo os financiamentos, empréstimos, capital dos proprietários, operações com leasing" etc.

Dessa forma, a DFC revela associações entre estas três categorias. Por exemplo, as operações de novos financiamentos e empréstimos estão ligadas aos pagamentos realizados no período referentes a este tipo de dívida contraída no passado, na seção atividade financeira. Dentro da seção atividade operacional há a indicação, a disponibilidade do caixa para cobrir as despesas, os juros, as retiradas da família etc.

Mostra ainda se a geração de caixa está sendo suficiente para cobrir os financiamentos na seção atividade financeira e assim sucessivamente.

Há necessidade de se fazer alguns ajustamentos no Lucro Líquido obtido na Demonstração do Resultado a base de competência para se comparar com o fluxo gerado pela caixa. Seria praticamente a comparação de um fluxo econômico com o financeiro.

Por exemplo, a depreciação é uma despesa não desembolsada pelo caixa, mas que reduz o lucro na Demonstração de Resultado a base de competência. Para reconciliar o Lucro Líquido com o caixa líquido, a depreciação deveria ser somada de volta ao Lucro Líquido. Um exemplo onde deveria haver adição à receita é o acréscimo referente a uma safra constante no estoque, no valor, por exemplo de $\$ 11.000$, incluso no Lucro Líquido. Todavia, pelo fato da colheita não ter sido ainda transformada em caixa, os $\$ 11.000$ de acréscimo de inventário teria que ser deduzido do Lucro Líquido para se chegar ao mesmo valor de caixa.

Esta reconciliação (exemplificada nos Anexos 1 e 2), é uma ferramenta muito útil para análise, principalmente das instituições que concedem crédito. Em pouco tempo se entenderá a saúde financeira da empresa relacionando-se com a situação econômica da mesma.

\section{3) Apuração do Lucro Rural pelo método Caixa "versus" o método de Competência}

Neste item mostramos as discrepâncias entre os regimes Caixa e Competência na apuração do resultado de uma atividade rural. Para tanto são utilizadas pelos pesquisadores Seger e Lins ${ }^{4}$ algumas propriedades rurais (180) como amostragem no estado de Illinois durante quatro anos. Os resultados indicam um percentual substancial nas diferenças entre as duas mensurações de lucro, ou seja, uma média anual de $88 \%$. Quando os dados do lucro são trazidos para uma média de 4 anos, a diferença cai para $36 \%$. Baseando-se neste estudo, fazendeiros e outros usuários que só trabalham com a base do caixa tem uma visão distorcida da verdadeira situação do negócio rural.

\footnotetext{
${ }^{4}$ Cash Versus Accrual Measures of Farm Income - Daniel J. Seger e David A. Lins - North Central Journal of Agricultural Economics. Vol.8. $\mathrm{N}^{0} 2$, Julho de 1986 - Illinois.
} 
A conclusão dos pesquisadores acima é que a Contabilidade pelo método Caixa deixa muito a desejar em relação ao método de Competência, e que as diferenças entre os dois métodos são muito maiores que normalmente os usuários pensam.

As principais mudanças segundo Dunn e Frey ${ }^{5}(5)$ de conversão do método Caixa para o de Competência são:

Lado do Ativo (mudanças positivas que adicionam o resultado por Competência):

Mudanças nos inventários de safra e sementes;

Mudanças nos inventários de animais vivos;

Mudanças em Investimentos pelo método de equivalência;

Mudanças nos suprimentos e manuseios;

Mudanças nas despesas antecipadas;

Mudanças no investimento do caixa durante as safras em crescimento;

Mudanças em contas a receber.

Lado do Passivo (Mudanças positivas que subtraem o resultado por Competência)

Mudanças em Contas a Pagar;

Mudanças nos impostos incorridos;

Mudanças nos impostos incorridos nos empréstimos imobiliários;

Mudanças nos aluguéis e "leasing" incorridos;

Mudanças nos juros incorridos e outras.

Para a transformação do método de Competência para o método Caixa é usada a seguinte fórmula - (outros métodos de conversão são usados além do proposto na página seguinte na transformação do resultado econômico em resultado financeiro):

Lucro (resultado) pelo método de Competência

- Mudança do Inventário [A]

- Mudanças nas Contas a Receber [B]

- Produtos Rurais Usados (consumidos na fazenda e não vendidos) [C]

+ Entrada de Produção Rural (sementes, soja. do estoque) [D]

- Variações nas Despesas Pagas Antecipadamente [E]

+ Mudancas nas Contas a Pagar

$[\mathrm{F}][$

= Lucro Líquido Financeiro (Caixa)

Para analisar a diferença entre os lucros pelo método Competência e Caixa, foram utilizados a média estatística, a média absoluta (indicadas abaixo, respectivamente) e a análise de regressão entre os dois métodos.

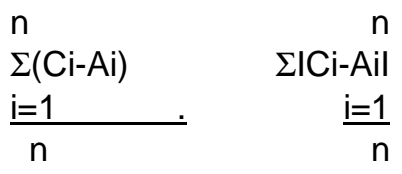

Onde C é o Lucro Rural Financeiro (Caixa), A é o Lucro pela base de Competência e $\mathrm{N}$ é o número de Observações.

Por exemplo, considerando as informações acima, em itens específicos da Contabilidade, os percentuais de flutuação obtidos pela média absoluta foram:
Anos
A
B
C
$\mathrm{D}$
$\mathrm{E}$
$\mathrm{F}$

5 Discriminant Analysis of Loans for Cash Grain Farm - Daniel J. Dunn e Thomas L. Frey Agricultural Finance Review, 36 (1976). 


\begin{tabular}{lrrrrrr}
1981 & $76.15 \%$ & $0.54 \%$ & $2.02 \%$ & $0.93 \%$ & $13.77 \%$ & $0.1 \%$ \\
1982 & $72.67 \%$ & $1.31 \%$ & $1.77 \%$ & $0.71 \%$ & $10.82 \%$ & $3.7 \%$ \\
1983 & $87.27 \%$ & $1.70 \%$ & $1.90 \%$ & $0.81 \%$ & $16.16 \%$ & $7.5 \%$ \\
1984 & $\underline{133.53 \%}$ & $\underline{25.72 \%}$ & $\underline{3.26 \%}$ & $\underline{1.84 \%}$ & $\underline{24.81 \%}$ & $\underline{12.0 \%}$ \\
\hline$\underline{\text { Média }}$ & $\underline{87.80 \%}$ & $\underline{5.32 \%}$ & $\underline{\underline{2.12 \%}}$ & $\underline{\underline{0.99 \%}}$ & $\underline{15.40 \%}$ & $\underline{5.6 \%}$
\end{tabular}

Como é observado neste quadro, as principais variações são referentes ao Inventário, item $\mathrm{A}$, atingindo uma média de praticamente $88 \%$.

Todavia, a variação significativa não inválida o método caixa, pois ele é muito importante para diversas decisões a serem tomadas no âmbito financeiro. O que é importante é não usá-lo de maneira isolada, mas sempre em conjunto com outras demonstrações ou ainda integrando-o com a demonstração econômica como proposto neste segmento.

\section{4) Análise do Fluxo de Caixa em Negócios Rurais}

A Demonstração do Fluxo de Caixa (DFC) proporciona informações necessárias principalmente para avaliar as atividades operacionais de um negócio rural. Se a análise for um conjunto com a Demonstração do Resultado do Exercício e o Balanço Patrimonial podem ser obtidas importantes informações sobre o fluxo de caixa. Normalmente, para uma boa análise, a DFC é dividida em três partes: operacional, investimentos e financeira (já tratados no item 2).

Importante estudo foi desenvolvido por Burckel, Daughtrev (ambos da Universidade Estadual do Mississipi) e Watters (da Universidade Estadual do Novo México) sobre análise do fluxo de caixa" ${ }^{6}$. O referido trabalho foi realizado após as recomendações da "Farm Financial Task",".

O estudo referido divide a análise em dois métodos: direto e indireto. A análise é desenvolvida considerando as três seções distintas e referenciadas acima: operacional, investimentos e financeira.

O método chamado direto (veja Anexo 3) tem como principal vantagem mostrar as entradas (receitas) e saídas (despesas] do caixa operacional. O conhecimento destes montantes facilita a projeção de fluxos futuros. A comparação da DFC com o fluxo econômico é recomendada. Por exemplo, os maiores recursos do recebimento do caixa para a operação da fazenda originaram-se da venda de gado e aves (49\%) e safras e sementes (37\%) conforme pode ser visto no quadro 1 do Anexo 3 . Estes dois produtos resultam em $86 \%$ do total do caixa recebido de clientes durante 0 ano. $O$ quadro 2 naquele Anexo identifica os maiores desembolsos do caixa: despesas gerais e administrativas e retiradas da família, em $40 \%$ e $30 \%$ respectivamente do total do caixa pago durante 0 ano. Caixa usado para pagar sementes constitui também uma significativa porção entre estes montantes propiciam informações valiosas para os usuários.

O estudo ainda mostra que os emprestadores de recursos gostam mais do método direto porque os montantes pagos e recebidos são particularmente importantes na avaliação das necessidades de empréstimos externos e a sua capacidade de retornar o pagamento destes empréstimos.

O método chamado indireto começa com o Lucro Líquido a base do regime de competência e os ajustes das transações das receitas e despesas que não afetam o caixa mas que refletirão no resultado econômico, fazendo assim uma reconciliação entre os dois fluxos no que tange - as atividades operacionais, como pode ser visto no Anexo 4 em seu exemplo 1.

A principal vantagem do método indireto é que focaliza a diferença entre o lucro líquido econômico (ORE) e lucro líquido financeiro (DFC) considerando as atividades operacionais.

\footnotetext{
${ }^{6}$ Analysing an Agribusiness Statement of Cash Flows - Daryl Burckel. Zoel W. Dughtrey e Michael P. Watters. Agribusiness - Vol. 7 - John Wiley \& Sons, mc. 1991.

${ }^{7}$ Recomendation of The Farm Financial Standards TasK Force - Financial Guidelines for Agricultural Producers. Texas A \& M University, College Station - Texas - 1991.
} 
A primeira finalidade do relatório financeiro é prover informações sobre o desempenho do negócio através da apuração do resultado (lucro ou prejuízo) e seus componentes. Investidores, credores e outros que estão preocupados com uma avaliação prospectiva do fluxo líquido de caixa estão muito interessados nestas informações. Eles estão muito interessados em conhecer quanto vão ganhar no futuro, acima de qualquer outra informação. Demonstrações financeiras que mostram somente receitas e pagamentos do caixa durante um curto período de tempo, como um ano, não podem adequadamente indicar se o desempenho do negócio está com o sucesso desejado.

Se o método indireto é usado, as variações líquidas no ativo atual são consideradas na seção operacional. Presumivelmente, estas considerações fornecem suficientes informações para analisar as principais mudanças nas contas do balanço. Contudo, para um ativo não circulante ou ativo permanente (e ainda contas do ativo chamado intermediário), com a exceção do rebanho de reprodução, acréscimos ou decréscimos brutos resultantes das entradas ou saídas do caixa são registrados na seção investimentos da DFC a fim de mostrar os específicos investimentos ou desenvolvimentos do negócio.

O procedimento é paralelo para o passivo com o intuito de analisar os empréstimos com uma entrada de caixa. Novamente, se o método indireto é usado, somente os acréscimos ou decréscimos líquidos do passivo são mostrados na seção operacional enquanto os montantes do fluxo de caixa de novos empréstimos e pagamentos de financiamentos são registrados na seção financiamentos da DFC para passivos de prazo longo e intermediário. Investimentos e financiamentos são mostrados no Anexo 4 no exemplo 2.

Uma outra abordagem apresentada neste estudo:

Os autores tratam a DFC como uma ferramenta para administradores. investidores e credores para importantes tomadas de decisões. Administradores podem usar a DFC para ajudar a melhorar os ganhos e crescimento do negócio. Percebendo como os lucros dos seus clientes estão aumentando, a expansão e prosperidade, investidores e credores estão especialmente interessados em saber do potencial do retorno dos seus créditos junto àqueles clientes. Para tanto, dois fundamentais usos da DFC são possíveis, conforme o trabalho em estudo:

a) análise do desempenho passado e b) análise de projeções para o futuro. Há um número de diversas outras abordagens disponíveis, porém o método apresentado neste estudo utiliza-se de índices de análise e modelos hipotéticos de análise da DFC.

$\mathrm{Na}$ análise do desempenho passado, a primeira meta é gerar informações adicionais para administradores, investidores e credores. Detalhes sumarizados proporcionam uma visão das atividades operacionais, investimentos e financiamentos para importantes decisões gerenciais. A análise do desempenho passado avalia as fontes do caixa, o uso do caixa e o crescimento e expansão do negócio.

No que se refere às previsões de fluxo de caixa operacional, diversas pesquisas contábeis tem sido realizadas. A maioria destes estudos utiliza-se de vários modelos matemáticos para as projeções anuais de fluxos futuros de caixa. Os autores, todavia, abordam as reconciliações com o lucro liquido apurado pelo regime de competência como um importante instrumento para projeções, baseando-se nos dados registrados no passado.

\section{ANEXO 1}

Estudo de Caso "The George Profit Farm”, adaptado de Thomas Frey e Arnold Oltmans

"George Profit" tem uma fazenda de 880 acres onde ele produz grãos e pecuária. Seu rebanho consiste em 60 bovinos e em média 1.800 porcos ao ano. Em 1 9X8 ele obteve um Lucro Líquido de \$51.688 dólares. Todavia, usando a Demonstração do Fluxo de Caixa podem ser 
reveladas informações sobre o negócio não evidenciadas na Demonstração do Resultado do Exercício que informou o lucro acima.

Por exemplo, na seção Caixa Operacional, é possível determinar se o Caixa que entrou referente a receita foi suficiente para pagar a despesa operacional, os juros, os impostos e as retiradas da família para sobreviver. George tem um caixa líquido de $\$ 47.688$ após ter pago as suas despesas em 19X8. (Anexo 2).

$\mathrm{Na}$ seção investimento observamos a utilização de $\$ 15.000$ do Caixa principalmente em decorrência de novos investimentos. Na seção Operações Financeiras notamos um Caixa líquido cujo pagamento principal foi praticamente o dobro das novas entradas. Isto reflete fortemente na capacidade de pagamento da fazenda. George realmente reduziu as operações de empréstimos para $\$ 33.000$ (comparando a liquidação de $\$ 46.000$ contra os novos recursos de $\$$ 13.000). No total o Caixa usado em $\$ 36.000$ indica um elevado pagamento de dívida para as instituições financeiras. O acréscimo líquido do Caixa foi de $\$ 3.312$ reconciliados com o Balanço Patrimonial:

$\begin{array}{ccc}\text { Balanço Patrimonial } & \text { Início de } 19 \times 8 & \text { Fim de 19X8 } \\ \text { Caixa } & \$ 5.000 & \$ 1.688\end{array}$

O desempenho da atividade refletido na Caixa em 19X8 indica claramente uma forte restituição de empréstimos e a capacidade de financiar as operações com as próprias receitas operacionais geradas no negócio. Todavia, como pode ser visto no anexo 2, na seqüência, não fica bem claro se os estoques foram vendidos a preços mais baixo e se permitiu mais contas a pagar com a finalidade de gerar caixa. Se isto for verdade, poderia ser visto nos dados da Demonstração de Resultado a base de regime de competência e, assim sendo, traria problemas no futuro para geração de caixa.

A proposta de Reconciliação vista naquele anexo 2 elimina rapidamente este risco. O primeiro sinal positivo é o Lucro Líquido de $\$ 51.688$, ou seja, $\$ 4.000$ a mais que o caixa líquido das operações. Nos ajustamentos realizados abaixo do "item receita" a safra, os animais em estoque e outros estoques aumentarem em \$11.000, significando um bom desempenho no futuro em termos de caixa. No item "despesas ajustadas", a depreciação de \$42.000 pode ser comparada com os novos investimentos mostrados na seção investimentos no valor de $\$ 30.000$.

Assim, uma boa utilização do caixa foi na reposição de bens de capital embora numa taxa inferior a depreciação. Isto certamente trará implicações em anos futuros. Toda esta análise seria enriquecida na comparação com fluxos projetados e na comparação com a demonstração do ano anterior. Veja, a seguir, os dois fluxos referidos, no anexo 2 que se segue:

\title{
Anexo 2 - Demonstração de Fluxo de Caixa
}

\author{
Fazenda "George Profit"- adaptado do estudo de caso "The George Profit Farm" de \\ Thomas Frey e Arnold Otmans (3)
}

Para o ano findo $19 \times 8$

Fluxo de Caixa decorrente das Atividades Operacionais

Caixa recebido referente a produção agropecuária 325.000

Caixa pago para compra de ração

Caixa pago referente às despesas operacionais

(19.312)

$(163.000)$

Juros pagos no ano

Contribuições e Impostos pagos

$(17.000)$

"Lucro Financeiro Líquido"

75.688

Caderno de Estudos no 09 - São Paulo - FIPECAFI, Outubro de 1993 
Retiradas para Manutenção da Família

Caixa Líquido Gerado pela Atividade Operacional

$(\underline{28.000})$

\section{Fluxo de Caixa Gerado pelos Investimentos}

47.688

Caixa recebido de vendas de gado reprodutor (cria)

Caixa recebido de vendas de implementos agrícolas

Desembolso na compra de gado reprodutor

Desembolso na aquisição de implementos agrícolas

Desembolso para plano de aposentadoria

Caixa Liquido Decorrente de investimentos

12.000

7.000

(2.000)

(28.000)

$(\underline{4.000})$

(15.000)

(24.000)

(46.000)

13.000

21.000

(36.000)

5.000

1.688

Caixa no final do período de $19 \times 8$

Reconciliacão do Lucro Líquido com o Caixa gerado na Atividade Operacional

Lucro Líquido Obtido na Demonstração do Resultado do Exercício

Ajustes:

Itens Referentes a Receita

Acréscimo na safra e animais de engorda (e outros estoques)

Decréscimo nas contas a receber da fazenda

Ganhos/Perdas de capital na venda de reprodutores e i. agrícolas

Total dos ajustes na receita para ser subtraído do L. Líquido

51.688

11.000

$(1.000)$

9.000

1.000

$\underline{42.000}$

43.000

(28.000)

47.688

\section{ANEXO 3 - Fluxo de Caixa}

Um exemplo de análise da arte operacional da Demonstração do Fluxo de Caixa

Fluxo de caixa - Atividade operacional

Caixa recebido de clientes (quadro1)

Caixa pago $\mathrm{p} /$ fornec. e empregados (quadro2)

Pagamento de imposto de renda

Pagamento de juros

Juros recebidos
Método Direto

$\$$

223.206 .00

$-82.834 .00$

$-25.620 .00$

$-23.680 .00$

2.100 .00

Caixa Líquido gerado da Atividade Operacional

93.172 .00

Quadro 1:

Caixa Recebido de Clientes durante o ano

Caderno de Estudos no 09 - São Paulo - FIPECAFI, Outubro de 1993 
Gado Bovino e Aves

5.098 .00

Recebimentos do Governo e Dividendos

Caixa recebido de clientes durante $o$ ano

\section{Quadro2}

Caixa Pago para Fornecedores e Folha de Pagamento

Despesa administrativa geral

\section{Sementes}

Retiradas da família

Compra referente á rebanho bovino e aves

Pagamento á empregados

Caixa pago á fornecedores e folha de pagamento
110.000 .00

82.145 .00

13.033 .00

6.640 .00

6.290 .00

223.206.00

$49.00 \%$

$37.00 \%$

$6.00 \%$

$3.00 \%$

$3.00 \%$

$2.00 \%$

$100.00 \%$

Anexo 3.1 - Análise do Caixa

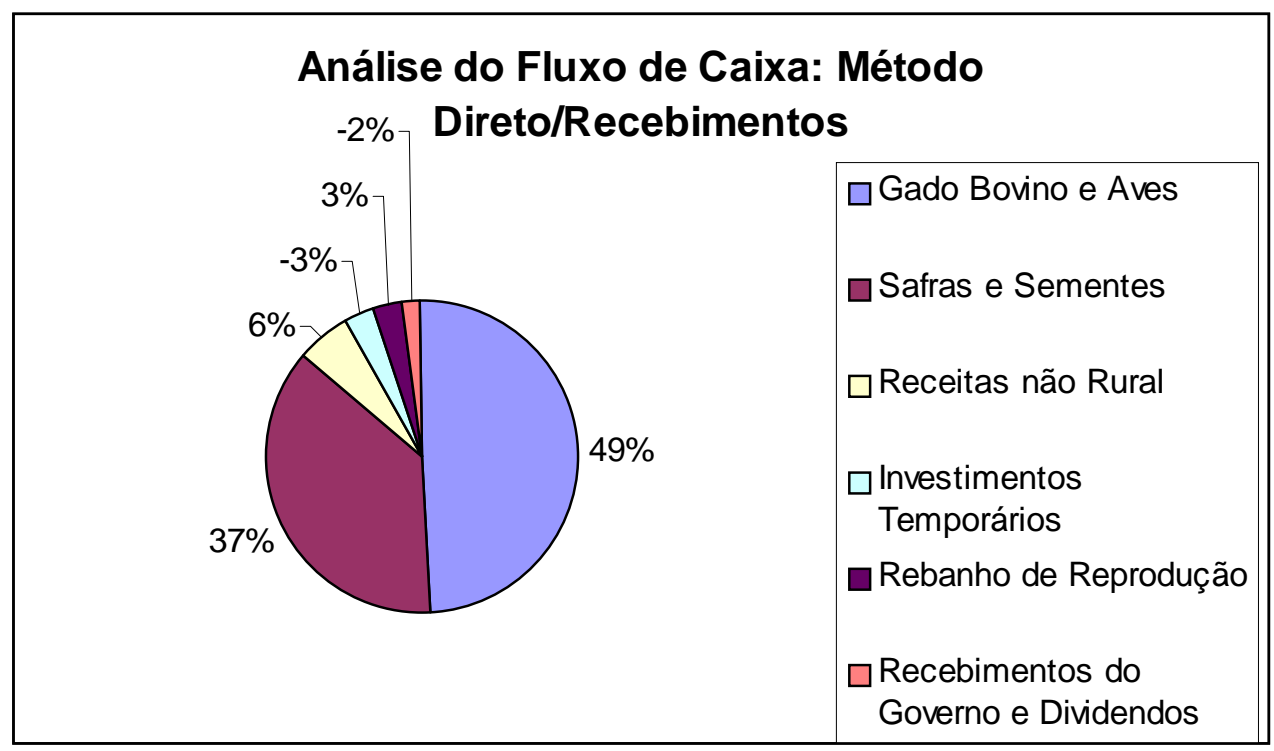

Anexo 3.2 - Análise do Caixa 


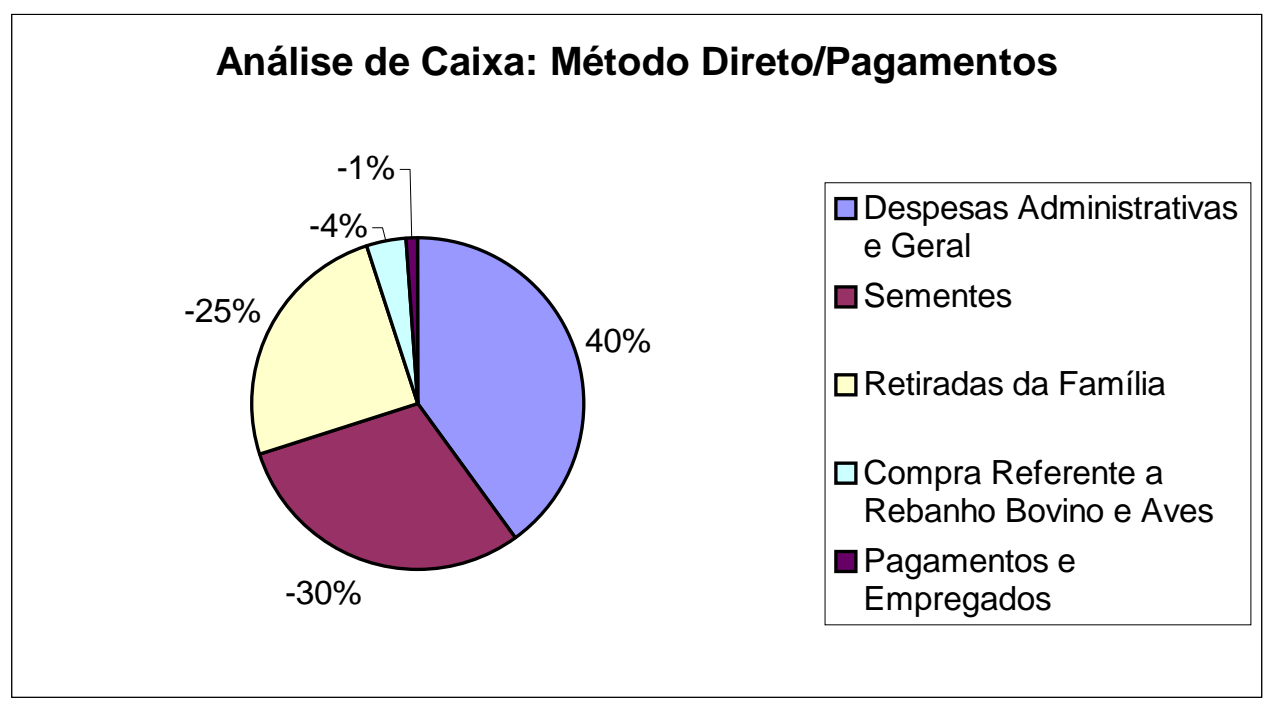

Anexo 4 - Análise/Fluxo-Caixa

1) Um exemplo da parte Operacional da Demonstração do Fluxo de Caixa:

Método Indireto

\section{Atividades Operacionais do Fluxo de Caixa}

Lucro Líquido

$\$ 64.747$

Ajustamentos para reconciliar o Lucro Líquido para

o.Caixa Líquido gerado na Atividade Operacional

- Depreciação e Amortização

$\$ 35.359$

- Ganho na Venda de Caminhão e Máquinas

$\$ 11.800$

- Perda na Venda do Rebanho Reprodutor

$\$ 4.000$

- Decréscimo nas Contas a Receber

$\$ 2.400$

- Decréscimo nas Contas a Pagar e Despesas Incorridas

$(\$ 1.534)$

Caixa Líquido Gerado pelas Atividades Operacionais

$\$ 93.172$

2) Um exemplo da parte de Investimentos e Financiamentos da Demonstração do Fluxo de Caixa

Caixa Líquido Gerado pela Atividade Operacional

(exemplo 1)

$\$ 93.172$

Caixa da atividade INVESTIMENTOS

- Originado da Venda de Gado Reprodutor

- Originado da Venda de Máquinas

- Originado da Venda de Caminhão Rural

- Pagamento por Compra de Máquinas

- Pagamento por Conta de Aposentadoria

- Outros Pagamentos

Caixa Líquido Gerado na atividade

Investimentos

$(\$ 19.210)$

Caixa da atividade FINANCIAMENTOS

Pagamento de Títulos de Curto Prazo

Pagamento de Títulos de Longo Prazo

Amortização de Financiamento

Caixa Líquido usado em atividade de

$(\$ 41.000)$

(\$29.970)

$(\$ 13.000)$

$\$ 9.500$

$\$ 11.000$

$\$ 800$

(\$47.500)

(\$1.950)

(\$1.060) 
Financiamento

$(\$ 83.970)$

Decréscimo Líquido no Caixa

$(\$ 10.008)$

Caixa no Início do Período

$\$ 33.000$

Caixa no Final do Ano

$\$ 22.992$

Estes exemplos foram adaptados do trabalho "Analyzing an Agribusiness Statement of Cash Flows" de: Daryl Burckel, Michael P. Watters e Zoel W. Daughtrey (6). 


\section{BIBLIOGRAFIA}

1) Agriculture Finance - An Introduction to Micro and Macro Concepts, John B. Penson Jr e David A. Lins - Prentice - Hall, Inc. 1980.

2) The Tax Reform Act of 1986

W. Ayer e Gayle S. Willett - Western Regional Extension, Publication 106, Dez/87 - Universidade de Arizona.

_- Thomas Frey e Arnold Otmans - AGRI Finance - 4/89 - Universidade de Illinois.

4) Cash Versus Accrual Measures of Farm Income, Daniel J. Seger e David A. Lins - North Central Journal of Agricultural Economics, Vol.8, $\mathrm{N}^{0} 2$, Julho de 1986 - Illinois.

5) Discriminant Analysis of Loans for Cash Grain Farm, Daniel J. Dunn e Thomas L. Frey, Agricultural Finance Review, 36 (1976).

6) Analvsing an Agribusiness Statement of Cash Flows, Daryl Burckel, Zoel W. Dughtrey e Michael P. Watters, Agribusiness - Vol. 7 - John Wiley \& Sons, Inc. 1991.

7) Recomendation of The Farm Financial Standards Task Force - Financial Guidelines for Agricultural Producers, Texas A \& M University, College Station

-Texas -1991. 